\title{
A Lei Orgânica de Segurança Alimentar e Nutricional (LOSAN) 2006: relatos, fatos históricos e processo de elaboração.
}

\section{The organic law of food and nutrition security (OLF- NS) 2006: reports, historical facts and elaboration process.}

\section{La ley orgánica de la seguridad alimentaria y la nutri- ción: informes, historia, hechos y procesos.}

RESUMO: Com a (re)organização do Conselho Nacional de Segurança Alimentar e Nutricional, o Estado brasileiro reconhece a responsabilidade de enfrentar as causas da fome e organizar um marco político legal para a garantia do direito humano à alimentação adequada. A configuração da política depende da regulamentação de uma lei orgânica, envolvendo a participação conjunta da sociedade civil e do Estado, e, ainda, incorporando a relação de interesses públicos e privados. O objetivo do presente trabalho foi analisar criticamente o processo histórico-político de elaboração da Lei Orgânica de Segurança Alimentar e Nutricional 2006. Trata-se de um estudo documental exploratório, analítico-qualitativo. Os dados secundários foram identificados e analisados a partir de busca documental; os dados primários foram analisados a partir de entrevistas semiestruturadas com informantes-chave. A aprovação da Lei Orgânica de Segurança Alimentar e Nutricional é a expressão de uma política pública afirmativa de direitos sociais, contudo não garante, por si só, a perspectiva da Segurança Alimentar e Nutricional. Conclui-se que há um longo percurso para operacionalizar os princípios da lei, que valem para todo o território nacional, marcado por heterogeneidade e desigualdades significativas. Além disto, a construção de valores e a consolidação da própria noção de direitos nas relações sociopolíticas que se processam no cotidiano das instituições são fundamentais.

Palavras-chave: Processos Políticos, Segurança Alimentar e Nutricional, Direito Humano à Alimentação Adequada, Participação Social, Políticas Públicas.

1 Universidade de Brasília - UnB

ISSN 1982-8829 Tempus, actas de saúde colet, Brasília, 11(4), 59-75, dez, 2017. Epub Ago/2018 
ABSTRACT: With the (re)organization of the National Council of Food and Nutrition Security, the brazilian State recognizes the responsibility to face the causes of hunger and to organize a legal political framework to guarantee the human right to adequate food. The configuration of the policy depends on the regulation of an organic law, involving the joint participation of civil society and the State, and, still, incorporating the relationship of public and private interests. The aim of this study was to analyze critically the historical-political process of elaboration of the Organic Law of Food and Nutrition Security (OLFNS) 2006. It's an exploratory, analytical-qualitative documentary study. Secondary data were identified and analyzed from documentary search and the primary data were analyzed from semi-structured interviews with key informants. The approval of the Organic Law of Food and Nutrition Security is the expression of a public policy affirmative of social rights, however it doesn't guarantee, by itself, the Food and Nutrition Security perspective. It is concluded that there is a long journey to operationalize the principles of law, which are valid for the whole national territory, marked by heterogeneity and significant inequalities. In addition, the construction of values and the consolidation of the notion of rights in the sociopolitical relations that are carried out in the daily life of institutions are equally fundamental.

Keywords: Political Processes, Food and Nutrition Security, Human Right to Adequate Food, Social Participation, Public Policy.

RESUMEN: Con la (re)organización del Consejo Nacional de Seguridad Alimentaria y Nutricional (CONSEA), el Estado brasileño reconoce su responsabilidad de abordar las causas del hambre y organizar un marco normativo legal para garantizar el derecho humano a una alimentación adecuada. La configuración de la política depende de la regulación de su ley orgánica, que implica la participación conjunta de la sociedad civil y el Estado, e incluso la incorporación de la relación de los intereses públicos y privados. El objetivo del presente trabajo es analizar el proceso histórico - la redacción de la Ley Orgánica política (SAN LOSAN) 2006. Este es un estúdio documental de exploración, analítica-cualitativa. Se identificaron y analizaron de búsqueda documental datos secundarios, los datos primarios fueron analizados a partir de entrevistas semiestructuradas con informantes clave. La aprobación de LOSAN es la expresión de una política pública positiva de los derechos sociales, pero sin embargo, no garantiza por sí la perspectiva de SAN. Llegamos a la conclusión de que hay un largo camino para poner en práctica los principios de la ley que se aplican a todo el territorio nacional, marcada por la heterogeneidad y las desigualdades significativas. Además, la construcción de valores y la consolidación de la noción de derechos en las relaciones socio-políticas que tienen lugar en la vida cotidiana de las instituciones son cuestiones claves.

Palabras-clave: Procesos Políticos, Seguridad Alimentaria y Nutricional, Derecho Humano a Alimentación Adecuada, Participación Social, Políticas Públicas.

\section{INTRODUÇÃO}

A Segurança Alimentar e Nutricional (SAN) é uma temática presente nas agendas políticas 
dos países há longa data. Há quase 70 anos, com a promissora emergência de ideias, movimentos e estatutos, a luta contra a fome e a concepção de um estado de segurança alimentar e bem-estar nutricional passaram a figurar como grandes desafios no ideário das sociedades civis e na agenda dos poderes públicos ${ }^{1,2,3}$.

Em 2003, com a (re)organização do Conselho Nacional de Segurança Alimentar e Nutricional (CONSEA), em nível institucional, o Estado brasileiro reconhece a responsabilidade de enfrentar as causas da fome e organizar um marco político legal para a garantia do direito humano à alimentação adequada ${ }^{4,5}$.

O marco legal institucional da Segurança Alimentar e Nutricional tornou-se realidade a partir da aprovação da Lei Orgânica de Segurança Alimentar e Nutricional (LOSAN), em setembro de 2006. A LOSAN criou o Sistema Nacional de Segurança Alimentar e Nutricional (SISAN), com vistas a assegurar o Direito Humano à Alimentação Adequada (DHAA) e, neste sentido, prevê ações baseadas nos princípios da universalidade e da equidade do acesso à alimentação adequada, com participação social na formulação e execução, no acompanhamento, monitoramento e controle das políticas e dos planos de ação em todas as esferas de governo, e a transparência dos programas, das ações e dos recursos públicos e privados, e dos critérios para sua concessão ${ }^{6}$.Em 2010, foi publicada a Política Nacional de Segurança Alimentar e Nutricional (PNSAN), que definiu as diretrizes e o Plano de Segurança Alimentar e Nutricional (PLANSAN) 7 , configurando, junto com a LOSAN, a tríade jurídico-legal da SAN no Brasil. Nesse contexto, o desafio do arranjo institucional tornou-se a articulação da política, do plano e do sistema de SAN com a viabilização de um conjunto de princípios capaz de promover a gestão única de ações articuladas em nível intersetorial, nos âmbitos das esferas federal, estadual e municipal do Estado, e sob a permanente participação da sociedade civil nas etapas de planejamento, gestão, monitoramento e avaliação, através dos conselhos e conferências de SAN.

O referencial teórico adotado para o SISAN sustenta uma perspectiva aberta que execute a articulação coordenada entre ações e programas descentralizados, com certo grau de interdependência. Ele pode potencializar as sinergias geradas pela própria interação entre os atores envolvidos em uma ação ou programa, que, por sua vez, podem originar iniciativas que vão além do proposto, inicialmente, através de cada ação tomada em separado ${ }^{8}$.A configuração da política depende da regulamentação da sua lei orgânica, com a prioridade de planejar espaços de inserção nas três esferas de gestão (federal, estadual e municipal), envolvendo a participação conjunta da sociedade civil e do Estado, e, ainda, incorporando a relação de interesses públicos e privados. A LOSAN demarca uma etapa decisória do processo político da SAN, a qual pode ser caracterizada como uma janela de oportunidade no contexto das políticas públicas afirmativas de direitos sociais no Brasil.

O objetivo do presente artigo foi analisar criticamente o processo histórico-político que planejou a LOSAN 2006. 


\section{METODOLOGIA}

O presente estudo foi parte integrante da tese de doutoramento intitulada Análise do processo de formulação da Política Nacional de Segurança Alimentar e Nutricional (2003-2006): atores, ideias, interesses e instituições na construção de consenso político. A publicação da PNSAN e do PLANSAN $^{7}$ só ocorreu posteriormente, em 25 de agosto de 2010, no Decreto $\mathbf{n}^{\mathbf{0}}$ 7.272. Todas as análises se debruçam sobre a LOSAN, que, na época, era o único pilar legal institucional temático, porém as discussões podem ter algum enlace com contexto histórico mais recente.

Trata-se de um estudo documental exploratório, analítico-qualitativo. A pesquisa qualitativa é um método científico apropriado para auxiliar a contextualização sócio-histórica e retratar a complexidade dos fenômenos sociais analisados, repletos de contradições, interconexões, determinações e causalidades, que acabam não sendo identificados pelos métodos quantitativos tradicionais ${ }^{9}$.

O caráter interdisciplinar dado à abordagem qualitativa, assim como a preocupação com os significados e as intencionalidades dos atores sociais, possibilitou um conhecimento particular e geral do processo analisado. $\mathrm{O}$ estudo buscou informações a partir de dados primários e secundários. Os dados primários foram provenientes de entrevistas individuais realizadas com informantes-chave do processo, e os dados secundários foram buscados através de análise documental.A pesquisa documental assemelha-se muito à pesquisa bibliográfica. Esta última utiliza-se fundamentalmente das contribuições de diversos autores sobre determinado assunto, enquanto a pesquisa documental utiliza-se, também, de materiais que não receberam tratamento analítico. As fontes da pesquisa documental são mais diversificadas do que as da pesquisa bibliográfica. Na pesquisa documental, existem os documentos de primeira mão, ou seja, aqueles que não receberam nenhum tratamento analítico, tais como os conservados em órgãos públicos e instituições privadas, e os documentos de segunda mão, que, de alguma forma, já foram analisados, tais como relatórios de pesquisa e relatórios de empresas, tabelas estatísticas e outros ${ }^{10}$.

Assim, foram utilizados, como fontes secundárias, documentos impressos e disponibilizados na internet referentes à SAN. Os principais documentos analisados foram leis, decretos, relatórios, discursos, atas de reuniões de conselhos, sites de programas institucionais etc.

A busca bibliográfica realizou-se na base Scielo, com os seguintes descritores: políticas públicas, segurança alimentar e nutricional, programas de alimentação e nutrição, direito humano à alimentação adequada, programas de combate à fome e à desnutrição, programas de transferência de renda, formulação de políticas, processos decisórios, conteúdo das políticas, programas, projetos, políticas e sistemas de SAN.A coleta dos dados primários foi realizada a partir de entrevistas semiestruturadas com informantes-chave, representantes do Estado e da sociedade civil. Os informantes-chave foram identificados a partir da confirmação de notório saber ou vivência profissional na temática da SAN. Todos manifestaram familiaridade com o tema e, obrigatoriamente, participaram de atividades relacionadas à SAN em instituições ou entidades.A técnica escolhida para apoiar o 
elenco de informantes-chave foi a denominada "bola de neve"11. A análise qualitativa por saturação permitiu ampliar ou reduzir a rede de informantes, conforme o esgotamento das respostas no conjunto dos entrevistados 9 .

Os informantes-chave foram: seis representantes do Estado (cinco do poder executivo e um do poder legislativo), seis representantes da sociedade civil (academia, fóruns estaduais e nacionais, movimentos sociais) e um representante de organismo internacional. Em termos de perda, houve duas recusas: uma do representante do setor produtivo e outra de um representante da sociedade civil, totalizando 13 das 15 entrevistas planejadas.Quanto à análise das entrevistas, foi utilizada a técnica qualitativa de análise de conteúdo proposta por Minayo 9 . A proposta busca os significados mais recorrentes nas falas dos entrevistados, realizando os seguintes procedimentos de análise dos dados primários: transcrição completa das entrevistas gravadas, objetivando a pré-análise do conteúdo; e constituição e preservação do "corpo" discursivo, para resguardar o contexto e a unidade das entrevistas e a identificação das categorias de análise.

Foram analisadas a configuração dos atores e instituições que participaram do processo, bem como a concertação de ideias e interesses vivenciados ao longo dos anos de 2003 a 2006, nas instâncias decisórias do CONSEA, incluindo o processo legislativo de aprovação no Congresso Nacional. Buscou-se caracterizar o processo evidenciando os fatos que determinaram o conteúdo político da LOSAN.

A LOSAN foi fruto de um processo longo, que culminou com sua aprovação em $2006^{12}$. Suas articulações históricas datam da década de 1990, com a realização da primeira conferencia de SAN, em 1994. Porém, para o presente estudo, foi feito um corte histórico a partir de 2003, quando, após a reconstituição do CONSEA, foi criado um Grupo de Trabalho (GT) ministerial para o planejamento e a elaboração da LOSAN como eixo estruturante do marco legal da SAN no Brasil.

\section{RESULTADOS}

Construção e tramitação do projeto de leiA proposta política de combate à fome, realizada pelo governo Lula, intitulada Estratégia Fome Zero, assumiu o debate da SAN como eixo estratégico de desenvolvimento, entendendo que o problema alimentar no País ia além da superação da pobreza e da fome. No discurso político inicial, o combate à fome deveria ser inserido nessa estratégia maior, por ser a face mais visível da insegurança alimentar e nutricional.A Estratégia Fome Zero foi impulsionada pelo governo federal para assegurar o direito humano à alimentação adequada às pessoas com dificuldades de acesso aos alimentos. Reuniu 33 programas sociais, em 4 eixos: acesso aos alimentos; fortalecimento da agricultura familiar; geração de renda; e articulação, mobilização e controle social. Seu foco principal era associar o objetivo da SAN a estratégias permanentes de desenvolvimento econômico e social, com crescente equidade e inclusão social ${ }^{12}$.

ISSN 1982-8829 Tempus, actas de saúde colet, Brasília, 11(4), 59-75, dez, 2017. Epub Ago/2018 
Porém, ao longo do processo político, não conseguiu articular o diálogo do combate à fome com a abordagem ampla da SAN e, assim, coube ao CONSEA o desafio de construir o marco legal da política $^{13}$.

O GT da LOSAN foi proposto em plenária do CONSEA, em dezembro de 2004, como um desdobramento das recomendações aprovadas na II Conferência Nacional de Segurança Alimentar e Nutricional (CNSAN). O GT que elaborou o texto da lei orgânica também acompanhou estratégias de socialização e debate da proposta. O primeiro fórum de debate ocorreu de outubro a dezembro de 2004, junto ao Encontro dos CONSEA estaduais. Na sequência, em abril de 2006, houve a realização de uma videoconferência, que apoiou a discussão da LOSAN e outros aspectos da SAN nos eventos preparatórios estaduais que antecederam o Encontro Nacional de Segurança Alimentar, chamada de Conferência +2 , em maio de $2006^{14}$.

Na plenária do CONSEA ocorrida em 26 de abril de 2005, foram definidos os princípios que norteariam o trabalho: (1) cumprir a principal determinação da II CNSAN; (2) buscar institucionalizar conquistas alcançadas, destacando o princípio do direito humano à alimentação adequada e à conceituação da SAN, conforme estabelecido na II CNSAN; (3) construir a intersetorialidade e a capacidade de interagir em regime de colaboração com outros sistemas ou políticas públicas já existentes; e (4) criar espaços plurais de concertação social, formulação e controle das políticas de SAN, por intermédio das conferências e dos CONSEA $^{14}$.

Os registros mostram claramente a intenção de construir uma proposta de lei enxuta, que indicasse os princípios norteadores para o funcionamento do SISAN, com a devida flexibilidade para aproveitar o momento político e prosseguir avançando na construção das outras etapas desse complexo e importante processo.

Como era complexo demais o problema [da SAN], a gente partiu de uma premissa, e é por isso que, em alguns fóruns, nós somos criticados. Então, o acordo inicial que a gente fez foi que a LOSAN ia, mais do que tudo, expressar princípios. Que ela não ia delimitar território, ela tinha de ser uma lei enxuta, curta, para dar o tom de como é que seria esse sistema aberto, mas não podia tecer detalhes. Senão, a gente não conseguia sair desse "atoleiro”. (informante-chave Estado)Os temas levados para a discussão em plenária, apesar de algumas controvérsias, foram consensuais: diziam respeito à natureza do CONSEA (se questionava se o caráter deste deveria ser propositivo ou deliberativo), bem como à sua composição (havendo proposições alternativas, entre uma composição paritária na representação entre Estado e sociedade civil, ou a atual composição de 2/3 da sociedade civil e 1/3 do Estado - poder executivo). Por fim, também foram discutidos os mecanismos de escolha dos representantes da sociedade civil, se através de nomeação pelo Presidente da República com base em indicações saídas da II CNSAN ou através da escolha direta dos representantes, pela CNSAN. Outro aspecto destacado foi a necessidade de estabelecer critérios para assegurar a representação, do ponto de vista de gênero, etnia, raça, denominação religiosa e região, no CONSEA. 
A LOSAN institui um CONSEA de caráter consultivo e propositivo, estabelecendo critérios para sua composição. A indicação de representação das populações negras e indígenas foi muito importante e garantiu a dimensão de equidade social de grupos tradicionalmente excluídos do cenário de políticas públicas no Brasil.O processo de concertação no grupo relator da lei apresentou momentos de tensão e, às vezes, impasses, demorando cerca de um ano para finalizar seus trabalhos.

As discussões eram abertas, inclusive, sempre se renovavam, cada vez que tinha reunião do grupo. Éramos poucos e sempre os mesmos. A gente fez vários processos de consulta para as redes de apoio [...] Os representantes de conselhos estaduais também fizeram suas proposições e nós fizemos um evento com os Estados, com essa discussão. (informante-chave Estado)A incorporação do enfoque da alimentação como um direito humano foi alvo de tensões e muitos debates no grupo. Assumir a SAN a partir de perspectiva da garantia do direito humano à alimentação adequada inseriu a dimensão dos sujeitos (titulares de direito) no conceito de SAN. A partir deste pressuposto, os objetos deixam de ser os alimentos, os estoques e os armazenamentos, e passam a ser as pessoas nas relação com os alimentos e seus valores, símbolos, atitudes, rituais e práticas alimentares. As pessoas passam a ocupar um lugar importante no campo da SAN, trazendo consigo a reflexão da dignidade humana no contexto da cidadania e de garantias fundamentais.As pessoas do CONSEA tinham muita resistência ao direito humano e à alimentação adequada. Acho que esse avanço, a gente conquistou mesmo [...] depois, com maturidade, a gente iria desdobrando; com a regulamentação, a gente avançava mais. Mas, se a gente acordasse o DHAA e se isso virasse lei, a gente saía de resolução de conferência e entrava já no rumo legal mesmo. (informantechave Estado)Nesse debate, o fato de a alimentação não ser reconhecida na Constituição Federal como um direito social tornou-se um problema. A importância de construir essa inserção configurou-se com um desdobramento futuro, o qual foi conquistado em 2010, com a aprovação da Emenda Constitucional 64, que inseriu a alimentação como uma das garantias fundamentais do cidadão brasileiro no capítulo 6 da Constituição Federal ${ }^{15}$.

A LOSAN instituiu um SISAN que propõe a formulação e a implementação de políticas e planos de SAN, e o estímulo à integração dos esforços entre governo e sociedade civil, bem como a promoção do acompanhamento, monitoramento e da avaliação da SAN no País ${ }^{6}$.Nesse âmbito, todas as ações que visem à garantia da SAN devem ter como princípio a universalidade e a equidade no acesso à alimentação adequada, sem qualquer espécie de discriminação; a preservação da autonomia e do respeito à dignidade das pessoas; a participação social na formulação e execução, no acompanhamento, monitoramento e controle das políticas e dos planos de SAN, em todas as esferas de governo; e a transparência dos programas, das ações e dos recursos públicos e privados, e dos critérios para sua concessão ${ }^{6}$.

Após a finalização do processo de redação, pactuação e aprovação, em plenária do CONSEA, a LOSAN seguiu seu trâmite rumo às etapas junto ao Congresso Nacional. As aprovações dos projetos de lei obedeceram um fluxo de análise nas duas casas do Congresso Nacional: Câmara de Deputados e Senado Federal. O CONSEA foi um agente pró-ativo de promoção e monitoramento dessas etapas.A participação política da base aliada do governo e do Ministério do Desenvolvimen- 
to Social e Combate à Fome foram igualmente importantes para o êxito do processo, que, tendo dado entrada na Câmara de Deputados em setembro de 2005, foi discutido e aprovado (com emendas na Câmara de Deputados e sem emendas no Senado Federal) em um exíguo período (político) de um ano.Nos eventos comemorativos da Semana Mundial de Alimentação de 2005, o presidente Luiz Inácio Lula da Silva assinou mensagem que encaminhava o projeto de LOSAN ao Congresso Nacional.A LOSAN foi aprovada em 13 de dezembro de 2005, na Comissão de Trabalho, Administração e Serviço Público da Câmara dos Deputados, como um tema "suprapartidário". O relatório de deputado de partido de oposição, com parecer favorável e três emendas, foi aceito por unanimidade na comissão.Em termos de participação popular, houve apoio público à aprovação imediata do projeto de lei, manifestado através de abaixo-assinado eletrônico, realizado no site do CONSEA e entregue ao Senado Federal, com milhares de assinaturas e o apoio de CONSEA estaduais como o de Minas Gerais, do Rio Grande do Sul, do Paraná e de São Paulo.Seguindo a tramitação no Senado Federal, o Projeto (número 0008/2006) foi aprovado, em 02 de agosto de 2006, na Comissão de Constituição, Justiça e Cidadania (CCJ). O projeto ainda foi apreciado na Comissão de Direitos Humanos e Legislação Participativa (CDH). Depois de aprovado, seguiu para votação no Plenário do Senado e Sanção Presidencial, em 15 de setembro de 2006.

O CONSEA fez um acompanhamento permanente através do sistema da Câmara de Deputados. Após cada etapa, era articulado o que fazer e quais as alternativas existiam. O importante foi ser pró-ativo e articulado com o Ministério do Desenvolvimento Social [MDS] e com a assessoria parlamentar do MDS, principalmente nas comissões do legislativo. Houve, também, apoio para os relatores (deputados) em termos de argumentos técnicos para fechar os relatórios. Agora, a interlocução política foi feita pelo Chico (presidente do CONSEA), os conselheiros e o MDS, também nos ajustes finais. (informante-chave Estado)Fica evidente que a organização e a posição estratégica dos atores (tanto do Estado quanto da sociedade civil) comprometidos com a SAN foram o mote que garantiu o êxito alcançado no seu processo de aprovação. A distribuição de atores sociais e políticos historicamente comprometidos com o tema, através de cargos e funções na relação do Estado com a sociedade civil, garantiu o arranjo político necessário para a consolidação do processo. Estratégia semelhante ocorreu no movimento de reforma sanitária das décadas de 1980-1990, na construção de uma política universal de garantia da saúde como um direito social.

[...] essa lei fortalecerá ainda mais a trajetória de significativos avanços que já estão ocorrendo, resultantes da ação conjunta do governo e da sociedade civil brasileira [...] com a lei e sua regulamentação, a SAN passa a ser uma política de Estado que aponta para a garantia do direito humano à alimentação [...] toda a trajetória de construção da nossa lei, ao lado da sociedade civil, revelou a imensa disposição de vencermos qualquer dificuldade, frente à vontade de conquistar um velho ideal. (informante-chave sociedade civil)

O conjunto de atores que participou do processo de formulação da LOSAN indicou, com clareza, o protagonismo das organizações da sociedade civil no processo, com destaque para o Fórum Brasileiro de Segurança Alimentar e Nutricional (FBSAN), no âmbito do CONSEA. É importante 
esclarecer que o FBSAN hoje possui a dimensão da soberania alimentar incorporada ao contexto da SAN, denominando-se Fórum Brasileiro de Soberania e Segurança Alimentar e Nutricional.

[...] é claro que a pressão, o papel indutor da sociedade civil, que está no CONSEA, vem do FBSAN. O FBSAN é quem pauta fundamentalmente o CONSEA. Os quadros que estão ali são consistentes, têm acúmulo de discussão no tema. (informante-chave sociedade civil)Eu acho que a sociedade civil foi o protagonista mais importante do processo, e oo CONSEA conferiu a institucionalidade necessária para que isso pudesse ter evoluído de uma forma organizada e produtiva. Não foram iniciativas isoladas. Foi um processo coordenado. Esse é o mérito do CONSEA! E, sem dúvida nenhuma, dentro do CONSEA tem mais a sociedade civil que a participação do Estado. (informante-chave Estado)As divergências de ideias e conflitos de interesses no processo decisório e de concertação político-social

As ideias e os valores perpassam a elaboração de políticas públicas. Isto porque definem não só o discurso governamental, mas, principalmente, a sua própria ação. Uma política pública também pode ser definida pelo conjunto de decisões tomadas para responder a um determinado problema da sociedade civil. Por isto, para entendê-las, é preciso considerá-las como um processo que contempla um fluxo de interações entre atores envolvidos na elaboração, implementação e avaliação dessas políticas. As decisões implicam, de outra parte, juízos de valor, ideias, interesses e conflitos que se processam em âmbito instituciona ${ }^{16}{ }^{16} \mathrm{Na}$ elaboração da LOSAN, a formação de consenso foi predominante e os conflitos de interesses, na maioria das vezes, harmonizados.

[...] a gente discutia objetivos, princípio, como é que seria a parte governamental, mas não tínhamos desacordo em geral. Talvez, as discussões mais tensas fossem: o conselho [CONSEA] tem que ser deliberativo? Não, não pode um conselho com 2/3 de sociedade civil ser deliberativo. (informante-chave Estado)Não, eu acho que não houve disputa ideológica porque não houve polêmica. A partir do momento que foi aprovado por unanimidade, houve uma habilidade política muito grande na condução desse processo a nível de Congresso [Nacional], para, talvez, não chamar a atenção daquilo que efetivamente se pretende com LOSAN. (informante-chave sociedade civil)Os grupos de interesses estão sempre tentando apresentar suas perspectivas sobre determinada questão a um formulador de políticas relevantes. Alguns destes grupos são bem organizados e têm uma boa base de recursos. Esta capacidade geralmente permite que consigam influenciar o processo de formulação de políticas mais do que outros grupos com menos recursos. Até certo ponto, os governos dependem de grupos de interesses com boa base de recursos para ajudá-los a decidir o que fazer em relação a uma questão específica. Os governos podem, também, depender bastante destes grupos ou indivíduos para ajudá-los na implementação de decisões relacionadas às políticas ${ }^{17}$.

Eu acredito nesse enfoque de concertação de interesses e formulação de políticas. Na minha visão, o papel das políticas públicas é esse. A sociedade civil precisa exercer pressão para o melhor funcionamento do Estado. Tem um autor, o Richard, ele diz assim: "a situação ideal é você ter bons governantes cercados de boas pressões, essa é a situação ideal”. O governo se constrói com pressões sociais, e se os governantes forem bons e as pressões forem boas, se tem uma combinação virtuosa. (informante-chave

ISSN 1982-8829 Tempus, actas de saúde colet, Brasília, 11(4), 59-75, dez, 2017. Epub Ago/2018 
sociedade civil)Levando em conta o relato dos entrevistados e os registros consultados, os interesses econômicos da indústria de alimentos e do setor do agronegócio formaram grupos de interesse contrários ao geral, no processo de construção da LOSAN.

A indústria de alimentos, então, esse é o grande conflito ideológico; então, no campo, o que tem de ideologia, pelo menos duas coisas, eu acho: a primeira, a relação com o Estado, a visão do Estado e a relação com o Estado [...]. (informante-chave sociedade civil)

Apesar de ter tido a Associação Brasileira das Indústrias de Alimentos (ABIA) como representante no CONSEA, esta, na Câmara de Deputados do Congresso Nacional, solicitou a retirada de pauta do projeto da LOSAN. A estratégia adotada pelo setor industrial de alimentos corrobora a impressão dos informantes-chave em relação ao conflito de interesses entre os princípios e diretrizes da SAN e o modelo agrícola-industrial vigente no País.Um grupo de interesse foi liderado pela ABIA, que, mesmo tendo participado das reuniões do CONSEA, enviou um parecer ao Congresso Nacional, afirmando que não precisava de lei de Segurança Alimentar e Nutricional porque já tinha uma legislação sanitária que contemplava essas questões, e propondo o arquivamento do projeto. (informante-chave sociedade civil)O aumento das assessorias parlamentares e a contratação de consultores externos é um reflexo da realidade de defesa de interesses do sistema político: o lobby. Empresas e entidades de classe contam com recursos humanos mais qualificados, e também deputados e senadores passam a depender cada vez mais de assessores especializados. A abordagem pode ser no sentido de proteção contra o assédio lobista, ou, dependendo da situação, aderir ou participar do jogo político ${ }^{18}$.

No enfoque contrário à proposta da SAN, o setor do agronegócio manifestou seu desagravo ao processo mediante o não comparecimento e a não participação nos espaços decisórios, como o CONSEA. A LOSAN assume a importância do fortalecimento da agricultura familiar e a adoção de um modelo agrícola de produção voltado para o mercado de consumo interno.

Um interesse claramente defendido no processo do CONSEA foi o da agricultura familiar, mas sempre fazendo a disputa com o agronegócio. Mesmo com os representantes do agronegócio ausentes. O setor do agronegócio não tinha vantagem nenhuma de se expor, o debate da SAN é um campo de desgaste e eles preferiram trabalhar no subterrâneo. (informante-chave Estado)As análises levam a crer que o agronegócio, as multinacionais do setor de alimentos, as redes de supermercados, os grandes setores de distribuição e as agroindústrias, principalmente, têm visões distintas do que a LOSAN defende. O forte questionamento do modelo agrícola-industrial atual coloca em risco seus interesses comerciais. Entende-se que, apesar da ausência do setor produtivo, a configuração do CONSEA garantiu um espaço de representação para a defesa de interesses de ambos os grupos.

A relação público x privado demanda um olhar cuidadoso no que diz respeito a conflito de interesses. Em termos de interdependência e autonomia, a relação do setor público com o setor privado requer uma regulamentação ética e transparente. 
Essa entrada do setor privado ao SISAN, ela tem que ser muito bem pensada, não é deixar a critério da responsabilidade social da empresa. Porque, se você tem um município pequenininho, com menos de 20 mil habitantes, e você tem uma grande empresa de agronegócio lá; e se ela manifestar interesse de entrada no SISAN, na Segurança Alimentar e Nutricional, como forma de marketing, de responsabilidade social: Quem vai fiscalizar? De que forma? Ela vai ter que atender os princípios do sistema. O sistema tem que ser único, em termos de princípios. Isso, para mim, é condição para garantia do direito humano à alimentação adequada. Se a gente não conseguir assegurar, na regulamentação, uma forma ética de conduzir a adesão do setor privado e, explicitamente, do setor privado alimentício, vai ser perigoso. (informante-chave Estado)É importante destacar que, nessa perspectiva, é preciso fortalecer a dimensão do controle democrático nos espaços de participação social relacionados à SAN, como, por exemplo, os CONSEA. As parcerias entre Estado e sociedade civil devem ter caráter complementar e não substitutivo do papel do poder público no enfrentamento da questão social. Iniciativas complementares são importantes, mas incapazes de dar conta de tal empreitada. As políticas públicas e os programas regionais não podem ser abandonados, retirando do Estado o compromisso da proteção social ${ }^{19}$.

É bom lembrar que, na ordem vigente, a sociedade encontra-se sob as condições constantes da crise estrutural do capital e, simultaneamente, da crise estrutural política. O grande desafio deste tempo, portanto, é descobrir como ampliar significativamente a margem de pensamento crítico como caminho para a construção de um projeto contra-hegemônico de sociedade ${ }^{20}$.Contudo, o CONSEA foi palco de inúmeros conflitos de ideias e interesses, mesmo entre seus pares e conselheiros. Pragmaticamente, não se configurou como um território neutro e imparcial perante o conjunto de ideias e interesses defendidos, mas, nem por isso, se negou a travar discussões políticas importantes, que dizem respeito às condições políticas, econômicas e sociais para a aprovação da LOSAN.Isso também se expressou nas falas de informantes-chave mais críticos ao processo:

Eu sou um tanto crítico ao texto da lei. Eu sei que foi proposital, que ele foi pensado em função do contexto desfavorável no Congresso [Nacional] ou de todas as pressões, barreiras ou dificuldades que nós poderíamos ter na tramitação do projeto de lei [...]. Seguramente, se fosse algo muito transformador, com uma expectativa de mudar muito as estruturas, possivelmente ele (o projeto de lei) não teria tido êxito na sua aprovação. Acho que se trabalhou muito no conceito da lógica do acesso, isso está bem posto no projeto de lei, mas ele não sinaliza a questão da política, não sinaliza a linha da implementação das políticas. A forma como esse projeto foi estruturado e aprovado gera um certo incômodo. (informantechave Estado)Seguramente, a Segurança Alimentar e Nutricional enquanto um tema da agenda política do governo federal não é um eixo orientador de políticas. Se fosse, certamente o governo não teria tomado medidas como a aprovação dos transgênicos. A própria questão do campo e da política agrícola, suas nuances, suas controvérsias e seus problemas... A questão da monocultura, a questão de um modelo que continua sendo excludente, concentrador de renda e tendo um alto impacto ambiental, altamente dependente do poder das transnacionais... Então, todos aqueles princípios que estão no contexto da discussão da soberania e Segurança Alimentar e Nutricional acabam orientando políticas dos ministérios do Desenvolvimento Social, do Desenvolvimento Agrário e, de uma pequena forma, da Saúde. Mas, com certeza, não orientam a política do Ministério da Agricultura e as macropolíticas de economia e planeja-

ISSN 1982-8829 Tempus, actas de saúde colet, Brasília, 11(4), 59-75, dez, 2017. Epub Ago/2018 
mento. (informante-chave Estado)Os informantes-chave identificaram um ponto de tensão nos debates: a soberania alimentar, a qual foi motivo de divergência política, antes mesmo do envio do projeto ao Congresso Nacional. Quando o projeto foi para a Casa Civil, o principal questionamento foi o termo soberania alimentar.

[...] essa relação entre Segurança Alimentar e Nutricional e soberania alimentar guarda um debate ideológico. Mas acho que esse debate está sendo superado. O que aconteceu foi que nós começamos a construir uma concepção de Segurança Alimentar pouco antes que o movimento internacional fizesse aparecer a concepção de soberania. No documento do governo paralelo, não beberam na fonte da soberania alimentar. O movimento de soberania alimentar surge muito marcado por essa visão crítica de apropriação feita pelos interesses privados, governos, a OMC [Organização Mundial do Comércio] e o Banco Mundial. (informante-chave sociedade civil)Antes de ser enviado para aprovação no Congresso Nacional, o projeto de lei original teve sua redação alterada nessa questão. A frase original citava soberania alimentar, mas, no texto emendado, o termo se apresenta com enfoque diferente. No projeto de lei original, o artigo quinto dispunha que "o direito humano à alimentação adequada requer a soberania alimentar da nação brasileira"; e, em seu parágrafo primeiro, indicava que "a soberania alimentar será alcançada por meio de políticas e estratégias sustentáveis de produção, comercialização e consumo de alimentos, respeitando-se as múltiplas características culturais". Já o parágrafo segundo indicava, ainda, que o exercício da soberania alimentar, pelo Estado brasileiro, deveria ser acompanhado do comprometimento do País para com a realização do direito humano à alimentação adequada de todos os povos.

Alvos de divergências e discussões, as emendas propostas resultaram nos artigos do texto aprovado na LOSAN $^{6}$ :

Art. $5^{\circ}$ - A consecução do direito humano à alimentação adequada e da Segurança Alimentar e Nutricional requer o respeito à soberania, que confere aos países a primazia de suas decisões sobre a produção e o consumo de alimentos;

Art. $6^{\circ}$ - O Estado brasileiro deve empenhar-se na promoção de cooperação técnica com países estrangeiros, contribuindo assim para a realização do direito humano à alimentação adequada no plano internacional.

Para alguns, o enfoque da soberania alimentar simboliza o componente ideológico-político do qual a LOSAN abre mão ao longo do processo. Mas, para outros, tal dimensão está garantida, pois faz parte do conceito.

$\mathrm{Eu}$ acho que a LOSAN perde um pouco quando não coloca essas duas palavras juntas (soberania alimentar). Você vê que as grandes derrotas do CONSEA foram em relação à soberania alimentar - por exemplo, os transgênicos. Nós não ganhamos nenhuma causa do governo Lula no campo da soberania alimentar. Aí é que eu penso: Será viável construir uma política de Segurança Alimentar no Brasil, 
sem soberania alimentar, se o Brasil não constrói sua própria soberania alimentar? (informante-chave Estado)Essa questão de soberania alimentar x SAN, eu acho que é um pouco preciosismo. Essa palavra soberania foi muito mais usada como palavra de afirmação de determinados grupos do que como uma grande diferença de um projeto estratégico. Não tem problema nenhum com a palavra soberania, mas, talvez, a agricultura, sei lá... mas eu não vi esse problema porque eu acho que a questão, que sempre foi colocada, foi como uma política nacional de Segurança Alimentar. Isso, automaticamente, remete à questão do próprio País. (informante-chave Estado)A forma de resolução do conflito sobre a soberania alimentar simboliza a capacidade de concertação existente, à época, entre os sujeitos e atores políticos que construíram a agenda da SAN. A LOSAN caracterizou-se como um pacto de possibilidades, a fim de ser um movimento de resistência e de enfraquecimento das políticas neoliberais e focalizadas, em geral. Houve, assim, um alto grau de consenso, a fim de garantir a SAN como uma política de Estado, com a negociação de limites e concessões, pois havia uma causa maior implícita para garantir e dar continuidade. Havia muito a ser feito...

Então, eu diria que não houve uma disputa de ideias, as divergências não eram disputas porque os atores da contradição estavam fora. Então, não tinha a disputa de modelo, todo mundo que estava ali, estava mais ou menos de acordo. Alguns achavam que o conselho tinha que ser 2/3 sociedade civil e deliberativo, e que tinha que botar na lei tudo que as empresas não podem fazer. As questões de conflito giraram em torno disso... (informante-chave Estado)O principal desafio se relacionava com as condições para a implementação política do marco legal da SAN. O êxito do processo de formulação foi compartilhado pela grande maioria dos participantes e militantes, em todas ou algumas fases dessa trajetória. Contudo, em que pese as conquistas políticas, a capacidade de gestão, manutenção e integração das ações seriam o que lhe configurariam as características inovadoras necessárias para o novo arranjo político proposto.

[...] na minha perspectiva, o foco central da SAN é de uma mudança estrutural, mudança de padrão de produção e de consumo, né? Mas, se isso aparecesse explicitamente, a lei não teria avançado. Então, eu acho que ela ficou muito mais na perspectiva do acesso. Ninguém vai se colocar contra a proposta de que qualquer cidadão ou qualquer indivíduo desprovido de cidadania possa ter acesso à alimentação. Então, a lei entra por um campo que tende a ter mais unanimidade. Certamente, não entrou-se em uma disputa no campo econômico. (informante-chave Estado)Na construção do processo, eu tenho que admitir que a LOSAN foi muito inteligente, mas insuficiente. A lei orienta e assegura princípios e diretrizes, mas, agora, como será implementado? Vai ser de forma mais intervencionista, mais reguladora ou de forma neoliberal - ou seja, não assegurando nada? (informante-chave sociedade civil)

\section{CONSIDERAÇÕES FINAIS}

O desafio de implementação do SISAN é imenso, pois, não obstante as adversidades e os enfrentamentos em relação às questões e aos interesses econômicos, a perspectiva de instituir um sistema intersetorial ainda é maior. A SAN não pode se resumir a um conjunto de políticas setoriais, pois é um eixo orientador de políticas que deve contribuir para que seus objetivos se incorporem ao conjunto de políticas públicas nacionais, que visem ao desenvolvimento social.As desigualdades 
inerentes ao sistema econômico e ao processo produtivo, inclusive de alimentos, são fatores determinantes da má alimentação e das desigualdades sociais. Portanto, para que as medidas neste campo possam ser resolutivas e deixem de ser apenas compensatórias de um problema gerado por um modelo de desenvolvimento excludente, é preciso ter coragem para enfrentar essa questão ${ }^{21}$.

O enfrentamento das desigualdades que demarcam o processo de insegurança alimentar e nutricional demanda mudanças. A potencialidade das proposições da LOSAN/SISAN incita alterações profundas nas estruturas política e econômica brasileiras. Este desafio se configura como de tamanha importância, seja por seu caráter universalista, seja por que pressupõe o alcance de bens públicos, como a sustentabilidade social, econômica e ambiental, o direito humano, os direitos de cidadania, a alimentação adequada e saudável, e a cultura, e estas categorias têm sido limitadas na agenda política brasileira, nas últimas décadas. Outro aspecto a destacar são os riscos que a opção de estruturar as ações da LOSAN de forma sistêmica (SISAN) pode ter. A forma de organização do SISAN não pode se pautar na lógica da adequação da oferta e da demanda, mercantilizando as ações propostas. As experiências existentes, que atestam, muitas vezes, a falência dos meios tradicionais de governo da coisa pública, não podem automaticamente definir ou levar à dedução de que o retorno radical à lógica do mercado seria a melhor solução. As características e os aprendizados da história brasileira na busca de formulação de mecanismos e caminhos para a transformação social precisam ser assimilados, no sentido da superação de limites dos projetos e da sua própria prática política $^{22}$. Para Campos $^{23}$, sanitarista do movimento de reforma sanitária que apoiou a organização da proposta do Sistema Único de Saúde (SUS), partir do pressuposto de que as relações de poder são "congeladas" em decorrência de uma reorganização administrativa sistêmica do Estado é assumir uma perspectiva conservadora, tanto do ponto de vista econômico quanto do político, pois implica aceitar passivamente o modelo e os limites já existentes.Por isso, não pode haver a ilusão de que, perante a estrutura política e institucional brasileira, a mera organização de um sistema de gestão seja suficiente para dar conta da complexidade da questão da SAN. As questões centrais são: Como garantir condições para o cumprimento pleno do DHAA, perante um modelo de desenvolvimento excludente? Qual a natureza de concessões, acordos e barganhas políticas necessárias para oportunizar essa transformação? Qual a capacidade institucional que as políticas públicas têm para o exercício concreto da intersetorialidade?Para Coitinho ${ }^{24}$, sob uma perspectiva de emancipação, não se pode ampliar o nível de satisfação das demandas sociais para além do ponto em que tal ampliação impeça a acumulação de capital global; por outro lado, não se pode reduzir o nível de satisfação abaixo do limite mínimo, a não ser que se rompam as regras da ordem política liberal democrática. Este limite esbarra positivamente na possibilidade de transformação social.Apesar do papel protagonista que a sociedade civil exerceu (e ainda exerce) no caminho de construção da SAN, é preciso reiterar o papel precípuo do Estado na garantia de direitos sociais. O Estado não é neutro e reflete uma relação intrínseca com as relações de produção capitalista. Não pode ser um bloco monolítico sem fissuras; é um campo estratégico, que organiza a unidade do bloco político no poder através do jogo de contradições presentes ${ }^{25}$. As lutas de interesses, contradições, convergências e confrontos ideológicos são expressões dessas relações, na dinâmica Estado-sociedade. 
Também não se pode esquecer que, historicamente, as discussões sobre SAN têm sido focalizadas e direcionadas aos grupos biológica e socialmente vulneráveis, sendo consideradas como políticas de combate à pobreza e à desigualdade social, e o que embasa o ideário da LOSAN é exatamente a necessidade de romper com este ciclo perverso de manutenção da desigualdade social.A aprovação da LOSAN é uma conquista social participativa, importante e afirmativa de direitos sociais, contudo não garante, por si só, a perspectiva da SAN. Há um longo percurso para operacionalizar localmente os princípios da lei, que valem para todo o território nacional, marcado por heterogeneidade e desigualdades significativas. Além disto, a construção de valores e a consolidação da própria noção de direitos nas relações sociopolíticas que se processam no cotidiano das instituições são passos igualmente fundamentais.O marco político legal de SAN não tem sido capaz de concretizar ações universais voltadas para o conjunto da sociedade civil brasileira que modifiquem a condição de acesso e escolha por uma alimentação saudável de maneira regular e permanente, em quantidade e qualidade, conforme estabelece a LOSAN.Hoje, transcorridos 11 anos de aprovação dessa lei, é importante analisar seu processo histórico-político de construção para identificar possíveis obstáculos e/ou potencialidades que auxiliem a redirecionar ou realinhar as perspectivas de implantação da LOSAN/SISAN, bem como os caminhos para a concretização dos seus princípios e diretrizes. A revisão e a atualização da política de SAN deve se dar à luz de um contexto político-social, e auxiliar a sociedade a ressignificar ou enfrentar os desafios necessários para a sua manutenção na agenda temática de prioridades do Estado.

O enfrentamento às ameaças políticas para a produção, o abastecimento, a comercialização e o acesso a alimentos saudáveis, sustentáveis, culturalmente referenciados, adequados à saúde e socialmente justos precisa se expressar no contexto das relações políticas e sociais. Os processos e as atividades que envolvem o sistema alimentar precisam encontrar correspondência nas práticas de escolha, seleção e preparo de alimentos; precisam dialogar com os valores envolvidos na identidade da comida como um patrimônio social e político; precisam criar mecanismos que possibilitem o exercício da soberania alimentar em suas diferentes dimensões: desde a seleção da semente, passando pela oferta e garantindo escolhas que dialoguem com a cultura alimentar dos diferentes grupos étnicos e sociais do Brasil.

\section{REFERÊNCIAS BIBLIOGRÁFICAS}

1. Silva AA. As relações do estado - sociedade civil e as formas de regulação social. In: Capacitação em serviço social e política social: módulo 2: política social. p. 57-71. Brasília: Cfess/Abepss/Cead/Ned-Unb, 1999.Maluf R, Menezes F, Valente F. Contribuição ao tema de segurança alimentar no Brasil. Cadernos de Debate, n. 4, p. 66-88, 1996.

2. Valente FLS. Direito humano à alimentação: desafios e conquistas. São Paulo: Cortez, 2002.Maluf R. Segurança Alimentar e Nutricional: conceitos fundamentais. Petrópolis: Vozes, 2007. $174 \mathrm{p}$.

ISSN 1982-8829 Tempus, actas de saúde colet, Brasília, 11(4), 59-75, dez, 2017. Epub Ago/2018 
3. Pinheiro ARO. Análise histórica do processo de formulação da política nacional de segurança alimentar e nutricional (2003-2006): atores, ideias, interesses e instituições na construção de consenso político. [tese] Brasília: Universidade de Brasília, 2009, 236 p.

4. Brasil. Lei ${ }^{\circ}$ 11.346, de 15 de setembro de 2006. Lei Orgânica de Segurança Alimentar e Nutricional. Cria o Sistema Nacional de Segurança Alimentar e Nutricional - SISAN com vistas a assegurar o direito humano à alimentação adequada e dá outras providências. Diário Oficial da União. 18 set. 2006. [internet]. [Acesso em 21 dez. 2016]. Disponível em: <https://www.planalto. gov.br/ccivil_03/_ato2004-2006/2006/lei/111346.htm>.Brasil. Decreto $n^{\circ} 7.272$, de 25 de agosto de 2010. Regulamenta a Lei no 11.346, de 15 de setembro de 2006, que cria o Sistema Nacional de Segurança Alimentar e Nutricional - SISAN com vistas a assegurar o direito humano à alimentação adequada, institui a Política Nacional de Segurança Alimentar e Nutricional PNSAN, estabelece os parâmetros para a elaboração do Plano Nacional de Segurança Alimentar e Nutricional, e dá outras providencias. Diário Oficial da União. 26 out. 2010. [internet] [acesso em 07 jan. 2017]. Disponível em: <http://www.planalto.gov.br/ccivil_03/_Ato2007-2010/2010/ Decreto/D7272.htm>.Burlandy L, Magalhães R, Maluf R. Construção e promoção de sistemas locais de segurança alimentar e nutricional no Brasil: aspectos produtivos, de consumo e de políticas públicas. [relatório de pesquisa]. Rio de Janeiro: 2006.

5. Minayo MCS, Assis SG, Souza ER (Orgs.). Avaliação por triangulação de métodos: abordagem de programas sociais.Rio de Janeiro: Fiocruz, 2005. 244 p.

6. Gil AC. Como elaborar projetos de pesquisa. 5. ed. São Paulo: Atlas, 2010.

7. Marques EC. Estado e redes sociais: permeabilidade e coesão nas políticas urbanas no Rio de Janeiro. Rio de Janeiro: Revan/Fapesp, 2000. 352 p.

8. Graziano J, Takagi M. Fome Zero: política pública e cidadania. In: Rocha M (Org.). Segurança alimentar: um desafio para acabar com a fome no Brasil. São Paulo: Fundação Perseu Abramo, 2004. 190 p.

9. Gomes JN. Segurança alimentar e nutricional como princípio orientador de políticas públicas no marco das necessidades humanas básicas. [tese] Brasília: Universidade de Brasília, 2007, 339 p.

10. Conselho Nacional de Segurança Alimentar e Nutricional - CONSEA. Ata da IX Reunião do CONSEA de 26 abr. 2005, p. 10. Brasília (DF): CONSEA, 2005.

11. Ação Brasileira pela nutrição e Direitos Humanos - ABRANDH. O direito humano à alimentação adequada e o sistema nacional de segurança alimentar e nutricional. Brasília, DF: Abrandh, 2013. [internet]. [Acesso em 10 jan. 2017]. Disponível em: <http://www.ideiasnamesa. unb.br/upload/bibliotecaIdeias/1391508593dhaasisan_miolo_030413.pdf $>$.Carvalho DBB de, 
Maltha D, Carvalho, DE Carmen, Sardinha LMV, Moura L de, Morais NOL, Vasconcelos AB, Pinheiro, ARO. Estudo de caso do processo de formulação da Política Nacional de Alimentação e Nutrição no Brasil. Epidemiol. Serv. Saúde [Internet]. 2011 Dez. [citado 2017 Jan. 16]; 20(4):449-458. Disponível em: <http://dx.doi.org/10.5123/S1679-49742011000400004>. Atkinson MM, Coleman WD. Policy networks, policy communities and the problems of governance, 5, p. 154-180, 1992.

12. Vianna MLTW. A americanização (perversa) da seguridade social no Brasil. Rio de Janeiro: Revan/Ipuerj-Ucam, 2000. 288 p.

13. Montaño C. Terceiro Setor e questão social: crítica ao padrão emergente de intervenção social. 2. ed. São Paulo: Cortez, 2003. 288 p.

14. Mészarós I. A teoria da alienação em Marx. São Paulo. Boitempo, 2006.Castro J. Geografia da fome: o dilema brasileiro pão ou aço. Rio de Janeiro: Civilização Brasileira, 2001. $318 \mathrm{p}$.

15. Pinheiro, ARO. Reflexões sobre o processo histórico-político de construção da Lei Orgânica de Segurança Alimentar e Nutricional. Segurança Alimentar e Nutricional, v. 15, p. 1-15, 2008. [internet] [Acesso em 10 jan. 2017]. Disponível em: <http://periodicos.sbu.unicamp. br/ojs/index.php/san/article/view/1813>.Campos GW de S. Reforma da reforma: repensando a saúde. São Paulo: Hucitec, 2006. 220 p.

16. Coutinho CN. Representação de interesses, formulação de políticas e hegemonia. In: Teixeira SF (Org.). Reforma sanitária: em busca de uma teoria. São Paulo: Cortez/Abrasco; 1989.

17. Poulantzas N. O Estado, o poder e o socialismo. São Paulo: Cortez; 2000.

Artigo apresentado em 23/02/17

Artigo aprovado em 11/03/18 Artigo publicado no sistema em 15/08/18 